\title{
Surgical Trends in Articular Cartilage Injuries of the Knee, Analysis of the Truven Health MarketScan Commercial Claims Database from 2005-2014
}

\author{
Nicholas A. Bonazza, M.D., Dallas M. Smuin, M.D., Rajat Joshi, B.S., Djibril Ba, M.P.H., \\ Guodong Liu, Ph.D., Douglas L. Leslie, Ph.D., and Aman Dhawan, M.D.
}

\begin{abstract}
Purpose: To evaluate trends in procedures for the treatment of chondral injuries of the knee using the MarketScan database in the hope that further work can be performed to refine the indications for chondral intervention Methods: The MarketScan Research Database was searched using Current Procedure Terminology, 4th edition, codes to identify patients who underwent chondral procedures of the knee from 2005-2014. Combined procedures, including meniscal transplant or osteotomy, were also identified. Patients were characterized by gender, age group and year of initial procedure. A $\chi^{2}$ test was used to evaluate differences in surgical trends between individual patient groups delineated by age and gender. The Cochran-Armitage trend test was used to identify significant differences in surgical trends yearly. Results: Of 148,373,254 unique patients, 520,934 patients underwent a total of 599,119 procedures. Arthroscopy with debridement/shaving of articular cartilage decreased in proportion from $75 \%$ of all procedures in 2005 to $51 \%$ of all procedures in $2014(P<.0001)$. Open osteochondral allograft saw the greatest change during the study period; a higher number of females than males underwent condral procedures $(P<.0001)$. Patients aged $45-54$ underwent the most procedures (32.9\% of all procedures). A total of 483 patients underwent chondral procedures in conjunction with meniscal transplant with variable incidence during the study period. A total of 1,418 patients underwent chondral procedures in conjunction with osteotomy; cumulative incidence decreased from 4.5 procedures per 1,000,000 patients/year in 2005 to 2.6 procedures per $1,000,000$ patients/year in $2014(P<.0001)$. Conclusions: Knee arthroscopy with debridement/shaving of articular cartilage remains the most common procedure performed. Although open allograft and autograft transplantation saw a sustained increase in incidence, the overall incidence of cartilage procedures, as well as those performed with osteotomies, declined. Level of Evidence: Level IV, cross-sectional study.
\end{abstract}

A rticular cartilage injury of the knee remains a challenging orthopaedic problem. The effects of chondral defects on patient pain and function have led

From the Department of Orthopaedics and Rehabilitation, Pennsylvania State University College of Medicine, Milton S. Hershey Medical Center, Penn State Health, (N.A.B., D.M.S., A.D.), Pennsylvania State College of Medicine, (R.J.), and; Department of Public Health Sciences, Pennsylvania State University College of Medicine, (D.B.,G.L.,D.L.L.,A.D.), Hershey, Pennsylvania, U.S.A.

The authors report that they have no conflicts of interest in the authorship and publication of this article. Full ICMJE author disclosure forms are available for this article online, as supplementary material.

Received June 11, 2019; accepted August 29, 2019.

Address correspondence to Aman Dhawan, M.D., 30 Hope Drive, Suite 2900, Hershey, Pennsylvania 17033, U.S.A. E-mail: adhawan@ pennstatehealth.psu.edu

(C) 2019 by the Arthroscopy Association of North America. Published by Elsevier Inc. This is an open access article under the CC BY-NC-ND license (http://creativecommons.org/licenses/by-nc-nd/4.0/).

2666-061X/19751

https://doi.org/10.1016/j.asmr.2019.08.002 to significant research efforts to develop effective treatments and understand the limitations of those treatments. ${ }^{1-4}$ Several studies have shown success with a variety of surgical techniques in a variety of patient populations. $^{5-11}$ There are limited randomized trials, however, to allow for effective comparison of the techniques that are most effective in treating isolated cartilage defects of the knee, specifically in adults. ${ }^{12}$ Furthermore, secondary to the limitations of available high-level studies, the incidence of procedures performed has not been well described, especially with regard to indications.

Additionally, there continue to be limitations in current techniques, including inconsistent outcomes and high rates of reoperation. ${ }^{12-15}$ This may be secondary to the poor understanding of the demographics of patients being treated and the indications for chondral intervention. Frank et al. ${ }^{12}$ found a reoperation rate for all patients undergoing microfracture, autologous chondrocyte implantation (ACI), osteochondral autograft 
transplantation or osteochondral allograft of $14.9 \%$ at 2 years with ACI, specifically, showing a 2 -year reoperation rate of $29.7 \%$. In another study, Frank et al. ${ }^{13}$ found a 5-year reoperation rate of $37 \%$ for patients undergoing osteochondral autograft transplantation. Thus, there continues to be debate regarding best practices, and practice trends continue to change as surgeons seek to improve current treatments with advancing techniques and refined indications. ${ }^{10,16-19}$ Despite questions regarding best practices and indications, McCormick et al. ${ }^{20}$ noted a 5\% annual increase in the number of cartilage surgical procedures between 2004 and 2011.

The purpose of our study was to evaluate trends in procedures for the treatment of chondral injuries of the knee using the MarketScan database in the hope that further work can be performed to refine the indications for chondral intervention. We sought to assess changes in the incidence of these procedures and the epidemiology of the patient population that has undergone these procedures as well as concomitant procedures such as osteotomies that have been performed in recent years in a larger database than previously studied. Our hypothesis was that microfracture and chondroplasty would remain the most common procedures performed for articular defects, although they would be decreasing in proportion to other procedures.

\section{Methods}

The MarketScan database is a medical and drug insurance claims database that contains inpatient and outpatient records and services from more than 100 insurance companies and large employers in the United health care system. The database contains information for more than 39 million individual patients for each year included in this study. The following Current Procedure Terminology (CPT), 4th edition, codes were used to search for patients undergoing the following procedures: 29,866 arthroscopy, knee, surgical; osteochondral autografts (e.g., mosaicplasty, which includes harvesting of the autografts); 29,867 arthroscopy, knee, surgical; osteochondral allograft (e.g., mosaicplasty); 29,877 arthroscopy, knee, surgical; debridement/ shaving of articular cartilage (chondroplasty); 29,879 arthroscopy, knee, surgical; abrasion arthroplasty (including chondroplasty when necessary) or multiple drilling or microfracture; 27,412 ACI, knee; 27,415 osteochondral allograft, knee, open; and 27;416 osteochondral autografts, knee, open (e.g., mosaicplasty, including harvesting of autografts).

Patient data were divided into frequency of each procedure type by year to examine yearly incidence. The frequency of all chondral procedures independent of individual CPT codes was recorded based on age group (0-17, 18-34, 35-44, 45-54, 55-64) and gender (male or female). The incidence of any chondral procedure performed in conjunction with meniscal transplant (CPT code 29868) or osteotomy (CPT codes $27448,27450,27454,27455,27457)$ was also identified.

A $\chi^{2}$ test was used to evaluate differences in surgical trends between individual patient groups divided by age group and gender. The Cochran-Armitage test was used to identify statistically significant differences in yearly surgical trends throughout the study period. All statistical tests were 2 -sided, and a $P$ value of less than 0.05 was considered statistically significant.

\section{Results}

A total of 520,934 patients of $148,373,254$ unique patients in the database underwent a total of 599,119 chondral procedures between 2005 and 2014 . Arthroscopy with debridement/shaving of articular cartilage was the most common procedure performed overall, making up $68.7 \%(411,423)$ of all procedures performed, but it decreased in proportion from $75 \%$ $(31,172 / 41,690)$ of all procedures in 2005 to $51 \%$ $(18,806 / 37,192)$ of all procedures in $2014(P<.0001)$. The second most commonly performed procedure was arthroscopy with abrasion arthroplasty of multiple drilling, or microfracture surgery, making up $29.2 \%$ $(175,021)$ of all procedures performed, but it increased in proportion over the study period from $24 \%(9,922 /$ $41,690)$ of all procedures in 2005 to $45 \%(16,754 /$ $38,584)$ in $2014(P<.0001)$. The rest of the examined chondral procedures combined to make up just $2.1 \%$ $(12,675)$ of total procedures performed during the study period.

The overall incidence of procedures was 4.04 procedures per 1,000 patients over 10 years, but incidence declined, specifically from 2009-2014, from 19 procedures per 10,000 patients to 7.9 per 10,000 patients. Open osteochondral allograft saw the greatest change during the study period, increasing $259 \%$ in incidence (Fig. 1) (Table 1). Both open osteochondral autograft, which did not have a CPT code until 2008, and arthroscopic osteochondral allograft increased $81 \%$ and $12 \%$, respectively, in incidence during the study period $(P<.0001)$. ACI $(-20 \%)$, arthroscopic osteochondral autograft $(-27 \%)$, chondroplasty $(-68 \%)$, and microfracture $(-10 \%)$ all saw decreased incidence in 2014 compared to 2005, although annual incidence varied throughout the study period (Fig. 1) (Fig. 2) (Table 1).

During the study period, females underwent more total chondral procedures $(311,918)$ than males $(287,205)(P<.0001)$. Females were more likely to undergo chondroplasty and were almost equally likely to undergo microfracture compared to males during the study period (Fig. 3).

Patients aged 45-54 underwent the most chondral procedures overall (32.9\% of all procedures). Overall, patients over the age of 45 accounted for $62.0 \%$ of all 
Fig. 1. Annual incidence of procedures.

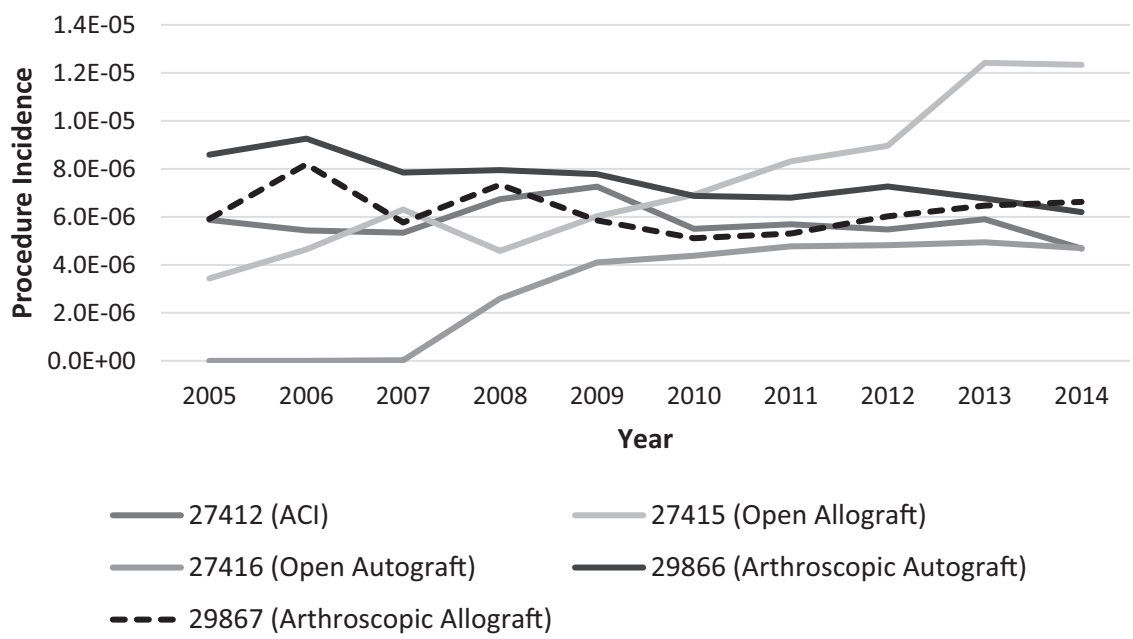

chondral procedures, whereas pediatric patients (age 17 or younger) made up just $4.4 \%$ of all procedures. Age preference varied by procedure, with ACI, open osteochondral allograft, open osteochondral autograft, arthroscopic autograft, and arthroscopic allograft procedures all peaking in the 18-34 age group $(P<.0001)$. Chondroplasty and microfracture, which were much more common overall, peaked in the 45-54 age group (Fig. 4).

A total of 483 patients underwent chondral procedures in conjunction with meniscal transplant; the incidence ranged from 8.9 procedures per 100,000 patients in 2012 to 14 procedures per 100,000 patients in 2014 (Fig. 5). Of these chondral procedures, open osteochondral allografts were the most commonly performed procedure in conjunction with meniscal transplant, making up $28.1 \%$ of all procedures. Arthroscopy with abrasion arthroplasty of multiple drilling or microfracture surgery was the second most commonly performed procedure in conjunction with meniscal transplant, making up $21.3 \%$ of all procedures. A total of 1,418 patients underwent chondral procedures in conjunction with osteotomy, decreasing in incidence from 4.5 procedures per 10,000 patients in 2005 to 2.6 procedures per 10,000 patients in 2014. During this period, arthroscopy with debridement/shaving of articular cartilage was the most common procedure performed in conjunction with osteotomy, making up $41.2 \%$ of all procedures. This was followed by arthroscopy with abrasion arthroplasty of multiple drilling or microfracture surgery, which made up $30.1 \%$ of all procedures performed in conjunction with osteotomy.

\section{Discussion}

The results of the study confirmed our hypothesis that chondroplasty and microfracture remain the most common procedures performed for articular cartilage lesions of the knee at $51 \%$ and $45 \%$ of procedures as of 2014. However, despite a decrease in the proportion of cases consisting of chondroplasty ( $75 \%$ in 2005 to $51 \%$ in 2014), microfracture actually increased from $24 \%$ of all cases in 2005 to $45 \%$ of all cases in 2014 . Although the incidence of microfracture remained stable over the study period, the incidence of chondroplasty decreased by $68 \%$. This is probably because of the decrease in these procedures used in isolation despite the clinical improvement shown when performed with appropriate indications. $^{21-23}$

Ignoring chondroplasty and microfracture, the incidence of other procedures increased from 2.38 procedures per 100,000 patients in 2005 to 3.45

Table 1. Annual Incidence of Procedure Performed and Total Number in Database

\begin{tabular}{llllllllccc}
\hline & \multicolumn{1}{c}{2005} & \multicolumn{1}{c}{2006} & \multicolumn{1}{c}{2007} & 2008 & 2009 & 2010 & 2011 & 2012 & 2013 & 2014 \\
\hline $\begin{array}{l}\text { Autologous chondrocyte } \\
\quad \text { implantation }\end{array}$ & $3.53 \mathrm{E}-03$ & $3.01 \mathrm{E}-03$ & $2.99 \mathrm{E}-03$ & $3.77 \mathrm{E}-03$ & $3.91 \mathrm{E}-03$ & $3.27 \mathrm{E}-03$ & $3.58 \mathrm{E}-03$ & $5.32 \mathrm{E}-03$ & $6.69 \mathrm{E}-03$ & $5.94 \mathrm{E}-03$ \\
Open allograft & & & & & & & & & \\
Open autograft & $2.06 \mathrm{E}-03$ & $2.58 \mathrm{E}-03$ & $3.53 \mathrm{E}-03$ & $2.56 \mathrm{E}-03$ & $3.25 \mathrm{E}-03$ & $4.11 \mathrm{E}-03$ & $5.23 \mathrm{E}-03$ & $8.71 \mathrm{E}-03$ & $1.41 \mathrm{E}-02$ & $1.57 \mathrm{E}-02$ \\
Arthroscopic autograft & $\mathrm{NA}$ & $\mathrm{NA}$ & $\mathrm{NA}$ & $1.45 \mathrm{E}-03$ & $2.21 \mathrm{E}-03$ & $2.60 \mathrm{E}-03$ & $3.00 \mathrm{E}-03$ & $4.68 \mathrm{E}-03$ & $5.60 \mathrm{E}-03$ & $5.97 \mathrm{E}-03$ \\
Arthroscopic allograft & $3.16 \mathrm{E}-03$ & $5.14 \mathrm{E}-03$ & $4.39 \mathrm{E}-03$ & $4.45 \mathrm{E}-03$ & $4.20 \mathrm{E}-03$ & $4.09 \mathrm{E}-03$ & $4.28 \mathrm{E}-03$ & $7.06 \mathrm{E}-03$ & $7.67 \mathrm{E}-03$ & $7.88 \mathrm{E}-03$ \\
Chondroplasty & $7.48 \mathrm{E}-03$ & $4.55 \mathrm{E}-03$ & $3.23 \mathrm{E}-03$ & $4.11 \mathrm{E}-03$ & $3.16 \mathrm{E}-03$ & $3.04 \mathrm{E}-03$ & $3.34 \mathrm{E}-03$ & $5.85 \mathrm{E}-03$ & $7.33 \mathrm{E}-03$ & $8.42 \mathrm{E}-03$ \\
Microfracture & $7.30 \mathrm{E}-01$ & $7.26 \mathrm{E}-01$ & $7.27 \mathrm{E}-01$ & $7.27 \mathrm{E}-01$ & $7.24 \mathrm{E}-01$ & $7.26 \mathrm{E}-01$ & $5.67 \mathrm{E}-01$ & $5.24 \mathrm{E}-01$ & $5.06 \mathrm{E}-01$ \\
Total annually & $2.38 \mathrm{E}-01$ & $2.55 \mathrm{E}-01$ & $2.59 \mathrm{E}-01$ & $2.57 \mathrm{E}-01$ & $2.56 \mathrm{E}-01$ & $2.59 \mathrm{E}-01$ & $2.55 \mathrm{E}-01$ & $4.01 \mathrm{E}-01$ & $4.34 \mathrm{E}-01$ & $4.50 \mathrm{E}-01$ \\
& 41690 & 57419 & 62595 & 73741 & 74124 & 76086 & 83016 & 54672 & 38584 & 37192 \\
\hline
\end{tabular}




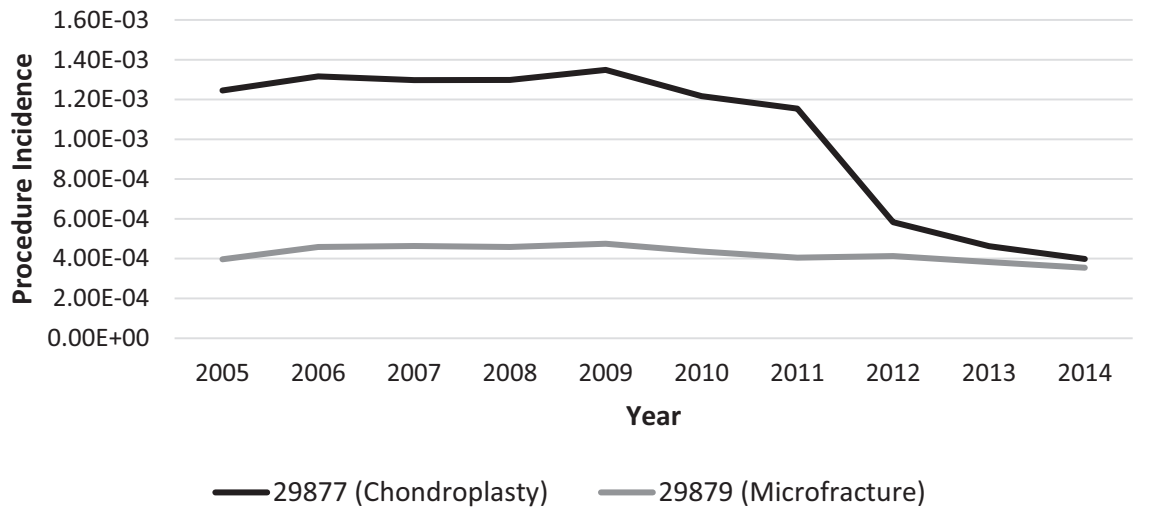

Fig. 2. Annual incidence of chondroplasty and microfracture. procedures per 100,000 patients in 2014. Specifically, open osteochondral allograft saw a 2.6 increase in incidence, and open osteochondral autograft saw a 0.8 increase, suggesting a shift toward increasing open chondral restorative procedures, specifically in younger patients, who most commonly underwent these procedures. Other chondral restorative procedures saw less of a change in incidence; arthroscopic allograft procedure incidence increased $12 \%$, whereas ACI and arthroscopic autograft procedures decreased by $20 \%$ and $27 \%$, respectively, in incidence over 10 years.

Previous studies have shown varying results with regard to trends in cartilage procedures of the knee. Gowd et al. ${ }^{24}$ saw a linear increase in both arthroscopic and open autograft and allograft procedures as well as ACI when looking at more than 15,000 procedures between 2010 and 2016 in the American College of Surgeons National Surgical Quality Improvement Program. The shorter time period and smaller number of procedures may explain the difference seen when looking specifically at arthroscopic autograft and ACI procedures during the same time period in our study.
Hancock et al. ${ }^{25}$ evaluated the trends in knee articular cartilage treatments in recently trained surgeons by using data from the American Board of Orthopaedic Surgery Part II database. Although Hancock et al. demonstrated a $46 \%$ decrease in the overall number of procedures performed between 2004 and 2013, our data demonstrated a $53 \%$ decrease in procedure incidence over a similar period ( 16.7 per 10,000 patients in 2005 to 7.9 per 10,000 patients in 2014). The overall distribution of cases in our larger representative population was similar; chondroplasty, microfracture and osteochondral grafting were the 3 most common procedures performed.

It is interesting that our results differed from those found by Montgomery et al., ${ }^{26}$ who used a different national commercial claims database, PearlDiver. These authors found minimal change in the overall incidence of cartilage procedures in the knee over a 6-year period, from 2004-2009 (1.27-1.53 cases per 10,000 patients; $P=.06)$ and found that males were more likely to undergo any procedure. Our data were consistent with their finding that microfracture and chondroplasty were the

Fig. 3. Distribution of procedures by gender.

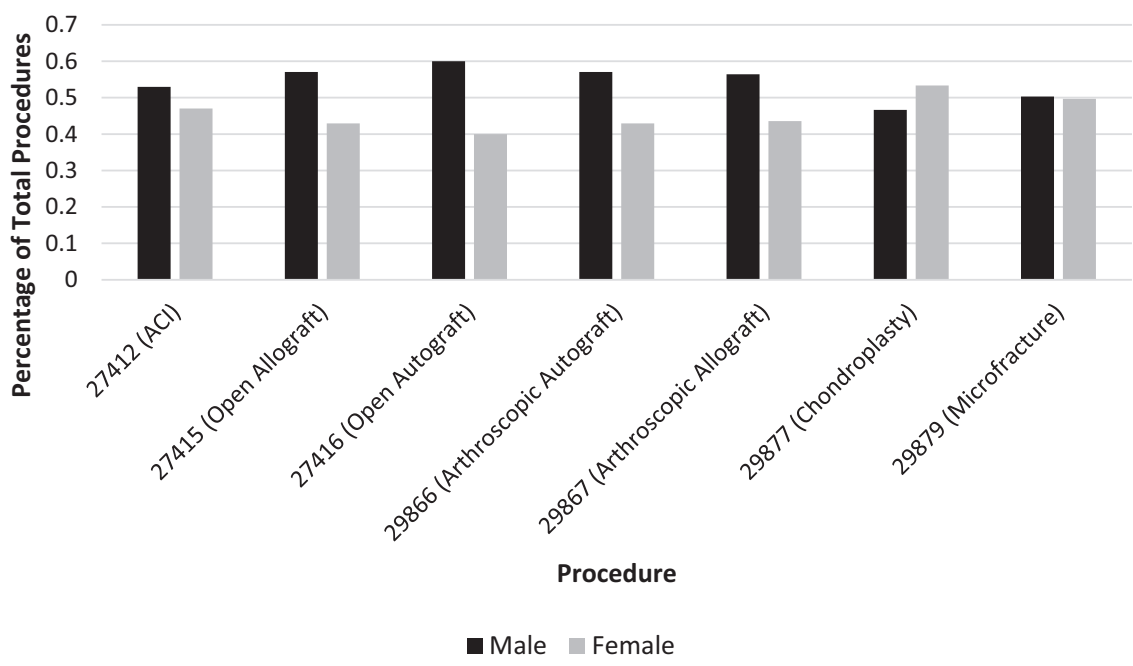


Fig. 4. Distribution of procedures by age group.

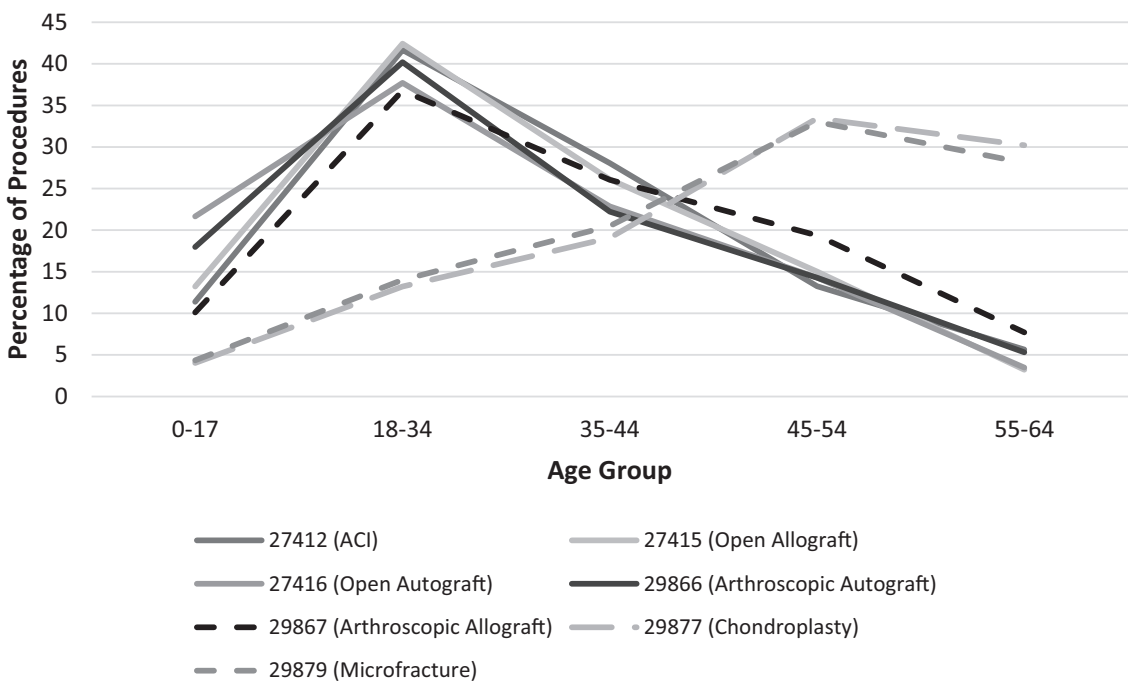

most common procedures performed and that patients older than 40 underwent a significant number of these procedures. Differences between the studies may be related to evaluation of a larger number of patients, more than 3.5 times larger in the MarketScan Research database, or to a longer timeframe (2005-2014), as well as to more recent data in the presented work.

Although the total number of procedures performed concomitantly with meniscal transplant remained steady throughout the study period, there was a $42 \%$ decrease in the number of procedures being performed concomitantly with osteotomies (4.5 procedures per 10,000 patients in 2005 to 2.6 procedures per 10,000 patients in 2014). The decreasing number of procedures may indicate narrowing indications for concomitant cartilage-regeneration procedures in patients with alignment deformities necessitating osteotomy. This may be secondary to multiple studies that have demonstrated mixed results with regard to outcomes, complication rates and reoperation rates following osteotomy. ${ }^{27-31}$

\section{Limitations}

Limitations of our study include the limited demographic and clinical details for the patients who underwent any procedure. Specifically, we did not consider patient factors, such as activity levels or clinical factors, such as mechanical alignment, concomitant pathology, or location, size or grading of the lesion, which can influence procedural decisions. Thus, we made the assumption that the distribution of clinical factors and lesion characteristics for patients present in the population were constant in each year of the study period.

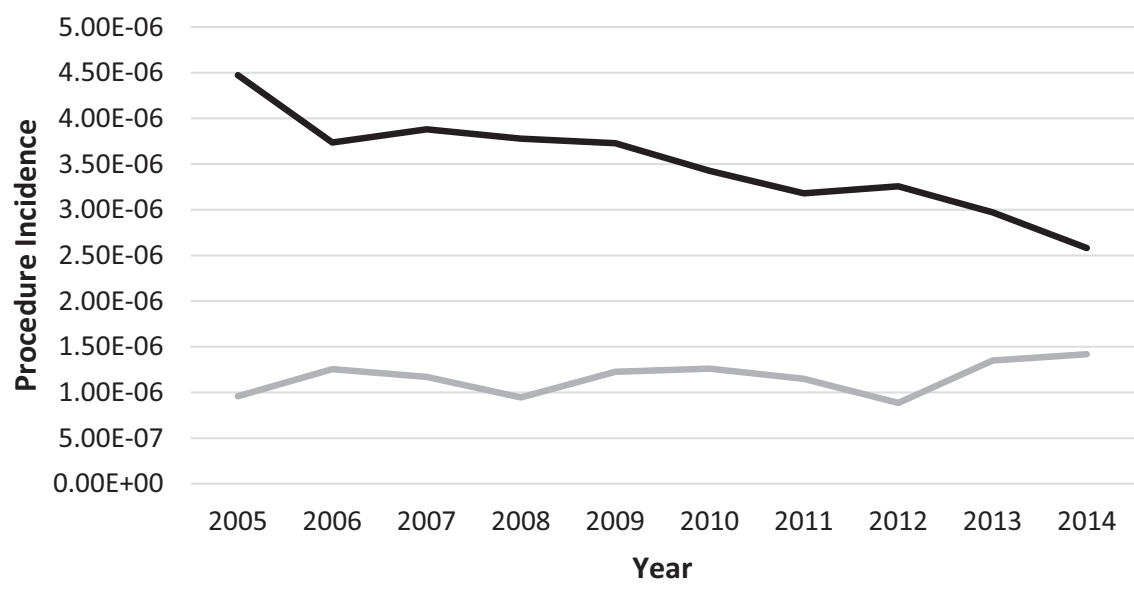

Fig. 5. Incidence of combined procedures with meniscal transplant or osteotomy. 
The population of patients studied each year also varies based on insurance coverage, employment and other factors that may affect a patient's presence or absence from the database. Additionally, we used an insurance and commercial claims database, so there is variability in who enters coding data concerning patients and in the accuracy of those data, depending on the source; that can cause error or bias in the database. The data are entered fundamentally for the purpose of financial remuneration, not for research or epidemiology. This discrepancy in purpose may create variability in the data and specifics available for each procedure. There also are changes in coding and reimbursement practices, such as the bundling of debridement of articular cartilage when done concomitantly with meniscectomy effected in 2011 , and that may alter the way in which these procedures are coded. Our chondroplasty data from later than 2011, thus, represents a conservative estimate; many more were probably performed but were bundled with concomitant procedures. Despite this, chondroplasty remained the most common cartilage procedure performed in 2014.

\section{Conclusions}

Knee arthroscopy with debridement/shaving of articular cartilage continues to be the most commonly performed procedure for chondral defects, although it is decreasing in proportion to other procedures; open osteochondral allograft showed the greatest increase in incidence between 2005 and 2014. Of chondral restorative procedures, only open allograft and autograft transplantation saw a sustained increase in incidence. Females and patients 45-54 years of age underwent the most procedures overall. Cartilage procedures had an overall incidence of 4.04 procedures per 1,000 patients over 10 years, but the incidence declined, specifically from 2009-2014, from 19 procedures per 10,000 patients to 7.9 per 10,000 patients. The incidence of cartilage procedures performed in conjunction with osteotomies decreased $42 \%$ over 10 years.

Institutional Review Board: A waiver was granted by the Institutional Review Board after review of the study's methodology.

\section{Acknowledgment}

The study was funded by an Orthopaedic Research Initiation Grant from Pennsylvania State University.

\section{References}

1. Heir S, Nerhus TK, Rotterud JH, et al. Focal cartilage defects in the knee impair quality of life as much as severe osteoarthritis: A comparison of knee injury and osteoarthritis outcome score in 4 patient categories scheduled for knee surgery. Am J Sports Med 2010;38: $231-237$.

2. Hirschmuller A, Andres T, Schoch W, et al. Quadriceps strength in patients with isolated cartilage defects of the knee: Results of isokinetic strength measurements and their correlation with clinical and functional results. Orthop J Sports Med 2017;5:2325967117703726.

3. Chahla J, Cinque ME, Godin JA, et al. Meniscectomy and resultant articular cartilage lesions of the knee among prospective national football league players: An imaging and performance analysis. Am J Sports Med 2018;46: 200-207.

4. Everhart JS, Abouljoud MM, Flanigan DC. The role of full-thickness cartilage defects in knee osteoarthritis (OA) incidence and progression: Data from the OA Initiative. J Orthop Res 2019;37:77-83.

5. Wang D, Kalia V, Eliasberg CD, et al. Osteochondral allograft transplantation of the knee in patients aged 40 years and older. Am J Sports Med 2018;46:581-589.

6. Balazs GC, Wang D, Burge AJ, Sinatro AL, Wong AC, Williams RJ III. Return to play among elite basketball players after osteochondral allograft transplantation of full-thickness cartilage lesions. Orthop J Sports Med 2018;6: 2325967118786941.

7. Tirico LEP, McCauley JC, Pulido PA, Bugbee WD. Does anterior cruciate ligament reconstruction affect the outcome of osteochondral allograft transplantation? A matched cohort study with a mean follow-up of 6 years. Am J Sports Med 2018;46:1836-1843.

8. Pareek A, Carey JL, Reardon PJ, Peterson L, Stuart MJ, Krych AJ. Long-term outcomes after autologous chondrocyte implantation: A systematic review at mean follow-up of 11.4 years. Cartilage 2016;7:298-308.

9. Wang D, Rebolledo BJ, Dare DM, et al. Osteochondral allograft transplantation of the knee in patients with an elevated body mass index. Cartilage 2019;10:214-221.

10. Lopez-Alcorocho JM, Aboli L, Guillen-Vicente I, et al. Cartilage defect treatment using high-density autologous chondrocyte implantation: Two-year follow-up. Cartilage 2018;9:363-369.

11. Brittberg M, Recker D, Ilgenfritz J, Saris DBF. Matrixapplied characterized autologous cultured chondrocytes versus microfracture: Five-year follow-up of a prospective randomized trial. Am J Sports Med 2018;46: 1343-1351.

12. Frank RM, McCormick F, Rosas S, et al. Reoperation rates after cartilage restoration procedures in the knee: Analysis of a large US commercial database. Am J Orthop (Belle Mead, NJ) 2018;47.

13. Frank RM, Lee S, Levy D, et al. Osteochondral allograft transplantation of the knee: Analysis of failures at 5 years. Am J Sports Med 2017;45:864-874.

14. Shaha JS, Cook JB, Rowles DJ, Bottoni CR, Shaha SH, Tokish JM. Return to an athletic lifestyle after osteochondral allograft transplantation of the knee. Am J Sports Med 2013;41:2083-2089.

15. Jaiswal PK, Bentley G, Carrington RW, Skinner JA, Briggs TW. The adverse effect of elevated body mass index on outcome after autologous chondrocyte implantation. J Bone Joint Surg Br 2012;94:1377-1381. 
16. Siebold R, Suezer F, Schmitt B, Trattnig S, Essig M. Good clinical and MRI outcome after arthroscopic autologous chondrocyte implantation for cartilage repair in the knee. Knee Surg Sports Traumatol Arthrosc 2018;26: 831-839.

17. Shimomura K, Yasui Y, Koizumi K, et al. First-in-human pilot study of implantation of a scaffold-free tissue-engineered construct generated from autologous synovial mesenchymal stem cells for repair of knee chondral lesions. Am J Sports Med 2018;46:2384-2393.

18. Bertho P, Pauvert A, Pouderoux T, Robert H. Treatment of large deep osteochondritis lesions of the knee by autologous matrix-induced chondrogenesis (AMIC): Preliminary results in 13 patients. Orthop Traumatol Surg Res 2018;104:695-700.

19. Chang NJ, Erdenekhuyag Y, Chou PH, Chu CJ, Lin CC, Shie MY. Therapeutic effects of the addition of plateletrich plasma to bioimplants and early rehabilitation exercise on articular cartilage repair. Am J Sports Med 2018;46: 2232-2241.

20. McCormick F, Harris JD, Abrams GD, et al. Trends in the surgical treatment of articular cartilage lesions in the United States: An analysis of a large private-payer database over a period of 8 years. Arthroscopy 2014;30: 222-226.

21. Anderson DE, Rose MB, Wille AJ, Wiedrick J Crawford DC. Arthroscopic mechanical chondroplasty of the knee is beneficial for treatment of focal cartilage lesions in the absence of concurrent pathology. Orthop $J$ Sports Med 2017;5:2325967117707213.

22. Spahn G, Kahl E, Mückley T, Hofmann GO, Klinger HM. Arthroscopic knee chondroplasty using a bipolar radiofrequency-based device compared to mechanical shaver: Results of a prospective, randomized, controlled study. Knee Surg Sports Traumatol Arthros 2008;16: 565-573.
23. Weber AE, Locker PH, Mayer EN, et al. Clinical outcomes after microfracture of the knee: Midterm follow-up. Orthopaed J Sports Med 2018;6:2325967117753572.

24. Gowd AK, Cvetanovich GL, Liu JN, et al. Management of chondral lesions of the knee: Analysis of trends and shortterm complications using the National Surgical Quality Improvement Program database. Arthroscopy 2019;35: 138-146.

25. Hancock KJ, Westermann RR, Shamrock AG, Duchman KR, Wolf BR, Amendola A. Trends in knee articular cartilage treatments: An American Board of Orthopaedic Surgery database study. J Knee Surg 2019;32:85-90.

26. Montgomery SR, Foster BD, Ngo SS, et al. Trends in the surgical treatment of articular cartilage defects of the knee in the United States. Knee Surg Sports Traumatol Arthrosc 2014;22:2070-2075.

27. Jung WH, Takeuchi R, Chun CW, et al. Second-look arthroscopic assessment of cartilage regeneration after medial opening-wedge high tibial osteotomy. Arthroscopy 2014;30:72-79.

28. Kim KI, Seo MC, Song SJ, Bae DK, Kim DH, Lee SH. Change of chondral lesions and predictive factors after medial open-wedge high tibial osteotomy with a locked plate system. Am J Sports Med 2017;45:1615-1621.

29. Jung WH, Takeuchi R, Chun CW, Lee JS, Jeong JH. Comparison of results of medial opening-wedge high tibial osteotomy with and without subchondral drilling. Arthroscopy 2015;31:673-679.

30. Hsu AC, Tirico LEP, Lin AG, Pulido PA, Bugbee WD. Osteochondral allograft transplantation and opening wedge tibial osteotomy: Clinical results of a combined single procedure. Cartilage 2017;9:248-254.

31. Leon SA, Mei XY, Safir OA, Gross AE, Kuzyk PR. Longterm results of fresh osteochondral allografts and realignment osteotomy for cartilage repair in the knee. Bone Joint J 2019;101-b:46-52. 